\title{
Evaluation of Uterine Cavity Abnormality using Saline Infusion Sonohysterography Before In Vitro Fertilization
}

\author{
Ichwanul Adenin, Hilma Putri Lubis* (D), Binarwan Halim \\ Department of Obstetrics and Gynecology, Division of Reproductive Endocrinology and Infertility, Faculty of Medicine, \\ Universitas Sumatera Utara, Medan, Indonesia
}

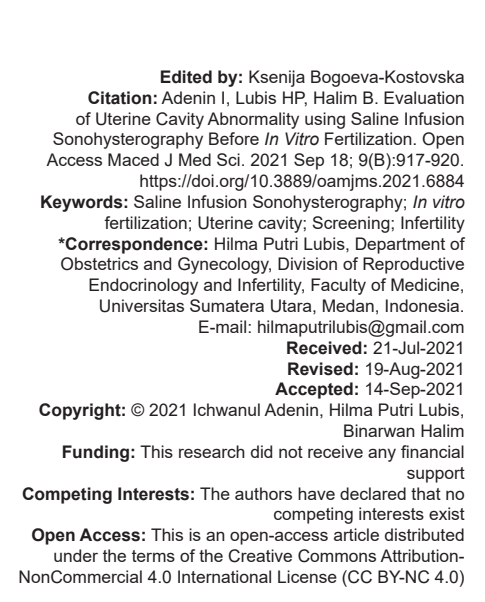

\begin{abstract}
BACKGROUND: Some studies suggested that saline infusion sonohysterography (SIS) has been used to detect uterine cavity abnormalities before in vitro fertilization (IVF) cycles to improve treatment success rates and decrease the number of cycle cancellations and embryo implantation failures. Some of the factors contributing to the dissemination and acceptance of the technique include the fact that it is a simple, less painful, less expensive, less invasive, and well-tolerated procedure when compared to hysteroscopy.

AIM: The aim of the study is to evaluate uterine cavity abnormality with SIS performed before IVF.

METHODS: A descriptive retrospective study involving 551 female partners who had SIS before IVF/ICSI treatment at private Halim Fertility Center from January 2014 until December 2017. Five hundred and fifty-one infertile woman was included in this study before IVF/ICSI cycles. Patients agreed to have an ultrasound assessment of the uterine cavity with the use of saline as the contrast medium. SIS procedure was scheduled postmenstrual period in the earlymid follicular phase and 1-3 months before starting IVF/ICSI treatment.

RESULTS: From 551 patients, we found 527 (94.4\%) cases with the normal uterine cavity. The uterine cavity abnormalities were detected in $5.56 \%$ of cases included in this study (28 $(5.02 \%)$ cases with endometrial polyps, two $(0.36 \%)$ cases with intrauterine adhesions, and one $(0.18 \%)$ case with Müllerian duct anomalies).

CONCLUSION: SIS before IVF treatment could be a good option for evaluating uterus cavity before IVF to improve success rates of pregnancy.
\end{abstract}

\section{Introduction}

Infertility is associated with the uterine cavity abnormalities that are thought to be a contributing factor of $10-15 \%$ of couples requiring treatment. An abnormal intrauterine finding is estimated to occur in about $34-62 \%$ of infertile women. Because of the high prevalence of uterine abnormalities, the evaluation of the uterine cavity is routinely performed on the basic evaluation of infertile women [1], [2]. The outcome of assisted reproductive technique largely depends on the receptivity of the endometrial lining of the uterus. Measures aimed at evaluating the uterine cavity before treatment are very vital for decision making and hence contribute to the overall success rate. The true prevalence of intrauterine lesions in infertile women is not known but some studies have reported an incidence of about $16-24 \%$ [3].

The diagnostic modalities that are commonly employed to evaluate the regularity and shape of the uterine cavity include a conventional 2-dimensional (2-D) and 3-D transvaginal scan, saline infusion sonography (SIS), hysterosalpingogram, and hysteroscopy [3], [4]. Over the last three decades, SIS has become an integral part of ultrasound imaging in gynecology. SIS is a technique that can show better visualization of the uterine cavity than conventional transvaginal ultrasound (TVS). SIS is done by inserting the liquid gradually into the uterine cavity through a catheter inserted into the cervix. Some of the factors contributing to the dissemination and acceptance of the technique include the fact that it is a simple, less painful, less expensive, less invasive, and well-tolerated procedure when compared to hysteroscopy [4], [5]. In addition, SIS can provide detailed information about the uterus and endometrium.

SIS is indicated in the evaluation of the uterine cavity of women with abnormal pre- and postmenopausal uterine bleeding, infertility, recurrent pregnancy loss, suspected uterine cavity abnormality, myoma, polyps, or synechiae. SIS should not be performed on women who are pregnant or women planning to become pregnant or in women with pelvic infection or unexplained pelvic tenderness. SIS with the use of TVS for evaluation of abnormal uterine bleeding was first described by BonillaMusoles in 1992 [5], [6], [7]. SIS provides the benefit that saline is a negative contrast during TVS and is also useful in the distention of the uterus from 
saline, as it may indicate structural abnormalities of the endometrium [5], [6], [7]. Nannini et al. (1981) describes the concept of synchronized SIS with TVS after the initial experience of increased uterine cavity features [7]. Small endometrial polyps or intrauterine adhesions may not be diagnosed in 2-D TVS. Implantation failure presents a major clinical challenge and is a cause of considerable stress to patients and clinicians in assisted reproductive technology. Even minor uterine cavity abnormalities, such as endometrial polyps, small submucous myomas, adhesions, and septa are considered to have a negative impact on the chance to conceive through in vitro fertilization (IVF).

Some studies suggested that SIS has been used to detect uterine cavity abnormalities before IVF cycles to improve treatment success rates and decrease the number of cycle cancellations and embryo implantation failures [3], [8]. The aim of the study is to evaluate uterine cavity abnormality with SIS performed before IVF.

\section{Materials and Methods}

A descriptive retrospective study involving 551 infertile females who had SIS before IVF/ICSI treatment at private Halim Fertility Center from January 2014 until December 2017. SIS was performed on individuals preparing for IVF who had not undergone uterine cavity evaluation through SIS for at least a year. Patients submitted to examination for other indications were excluded from the study.

\section{Technique of SIS}

SIS procedure was scheduled during the follicular phase (ideally on day 10) after menstrual flow has ceased and 1-3 months before starting IVF/ICSI treatment, when the endometrium was relatively thin and the endometrial polyps could see clearly.

Preparation for the examination involved counseling about the procedure and obtaining informed consent. SIS is performed in the lithotomy position, with a full bladder and using TVS. After speculum placement and visualization of the cervix and external orifice, the cervix was prepped with povidone-iodine. The catheter was placed at the external cervical os and then advanced into the endometrial cavity. Then the speculum was carefully removed and the transvaginal probe was inserted into the vagina toward the posterior catheter. We used foley catheter No. 8, when the catheter was inserted, the catheter balloon was filled slowly with 10-30 $\mathrm{mL}$ saline solution once the balloon full, the endometrium was seen in the longitudinal direction, the uterine cavity was filled with saline solution. Using conventional 2D TVS, the anechoic fluid juxtaposed against the echogenic endometrium was visualized, providing a clear image of the uterine lining. At this time, an evaluation of the uterine cavity may be an endometrial polyp, intrauterine adhesions, congenital abnormalities of the uterus, and submucosum uterine myoma. At the end of the examination, the catheter balloon was emptied and then the catheter was removed from the cervix with a TVS guide. The cavity was deemed abnormal when polyps, submucous myomas, synechiae, or Müllerian duct anomalies were detected. The cases suspected of cavity abnormalities that might interfere with the outcome of IVF were referred for hysteroscopy.

Data were analyzed by computer applications in accordance with processing and analyzing data were using SPSS 17 (Statistic Package for Social Science) software. The main outcome measure of the study was SIS findings.

\section{Results}

From January 2014 and December 2017, we included 551 infertile women in this study. The mean age of the women was $34.17 \pm 5.16$ years and body mass index was $24.90 \pm 4.14 \mathrm{~kg} / \mathrm{m}^{2}$. Duration of infertility was $7.00 \pm 4.30$ years and most of the etiology of infertility was mixed factor $285(51.72 \%)$ and type of infertility was primary 450 (81.67\%) (Table 1).

Table 1. Demographic data of the patients

\begin{tabular}{ll}
\hline Characteristic & $\mathrm{n}=551$ \\
\hline Female age $(\mathrm{yo})(\mathrm{mean} \pm \mathrm{SD})$ & $34.17 \pm 5.16$ \\
Body mass index $\left(\mathrm{kg} / \mathrm{m}^{2}\right)($ mean $\pm \mathrm{SD})$ & $24.90 \pm 4.14$ \\
Duration of infertility (years) (mean $\pm \mathrm{SD})$ & $7.00 \pm 4.30$ \\
Type of infertility & \\
$\quad$ Primary & $450(81.67 \%)$ \\
Secondary & $101(18.33 \%)$ \\
Etiology of infertility & \\
$\quad$ Male factors & $161(29.22 \%)$ \\
Female factors & $105(19.06 \%)$ \\
Mixed factors & $285(51.72 \%)$ \\
\hline
\end{tabular}

From Table 2, from Five hundred and fifty-one infertile woman underwent hysterosonography within the time period comprised in the study. No abnormalities in the uterine cavity were seen in 519/551 of the cases (94.2\%). Examination revealed endometrial polyps in 29 cases $(5.26 \%)$, synechiae in two $(0.36 \%)$, and Müllerian duct anomalies in one $(0.18 \%)$.

Table 2: SIS Findings before IVF

\begin{tabular}{ll}
\hline SIS findings & $\mathrm{n}(\%)$ \\
\hline Normal & $519(94.2)$ \\
Endometrial polyps & $29(5.26)$ \\
Synechiae & $2(0.36)$ \\
Mullerian duct anomalies & $1(0.18)$ \\
\hline IVF: In vitro fertilization &
\end{tabular}




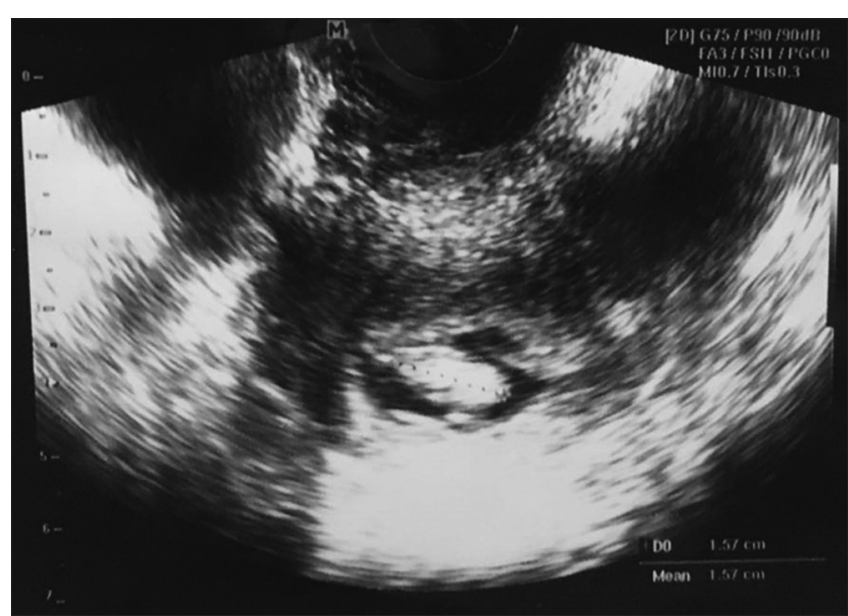

Figure 1: The distention of the uterine cavity produced after the infusion of saline solution. An endometrial polyp measuring $15.7 \mathrm{~mm}$ can be seen on the back wall

\section{Discussion}

In this study, uterine cavity abnormalities were found in $5.8 \%$ of the infertile patients submitted to SIS before IVF. Complications arising from the procedure were minor and not life-threatening.

The most common abnormalities in the uterine cavity findings were endometrial polyps, followed by synechiae and Müllerian duct anomalies. This finding agrees with the results published in another study, in which $13.3 \%$ of 60 infertile women analyzed had abnormalities on SIS (Sitimani et al., 2016) [9]. Lopes et al. found that from 170 cases, normal test results were seen in $86.3 \%$ and $14 \%$ with anomalous findings [10].

Endometrial polyps were the most frequent pathologic finding in SIS in this study (Figure 1). Our study was similar to other studies reported that endometrial polyps as the most prevalent finding $(12.5 \%)$ and $(9.1 \%)$ (Vilela et al. 2012 and Lopes et al. 2017) [10], [11]. Radwan et al. (2014) performed a study that included 241 infertile women to evaluate the presence of endometrial polyps. The patients were submitted to hysterosonography and hysteroscopy, and the sensitivity, specificity, and accuracy in the detection of endometrial polyps by hysterosonography were $97.3 \%, 95.8 \%$, and $96.2 \%$, respectively [12].

In this study, intrauterine synechiae were the second most common finding $(0.36 \%)$. This percentage was similar to what is found in the literature, with values ranging between 1.7\% and 2\% (Gupta et al., 2016; Sitimani et al., 2016) [9], [13]. Other authors reported lower incidences of uterine cavity disorders, with endometrial polyps and myomas seen in 5\% and synechiae in $1.7 \%$ of patients (Sitimani et al., 2016) [9].
Lopes et al. (2017) found that intrauterine synechiae in $3.5 \%$ of patients [10].

From this study, we also found Müllerian duct anomalies in $0.18 \%$ of patients. This percentage is similar to another study, with values of $0.5 \%$ (Lopes et al. 2017) [10]. Sallam (2016) found that saline sonohysterography was diagnostic of the bilateral tubal block with a sensitivity of $100 \%$, a specificity of $91.3 \%$, a PPV of $71.9 \%$, NPV of $93.4 \%$, FPR of $10.2 \%$, and FNR of $7 \%$ and also, he found that the pregnancy rate and ongoing pregnancy rate were higher in the group who underwent IVF/ICSI with prior saline sonohysterography than the group who underwent ICSI without a prior saline sonohysterography $(49 \%$ vs. $36 \%$ vs. $37 \%$ vs. $26 \%$ ) [14]. Obajimi et al. (2016) found that forty-six percent of the patients had intra-uterine pathologies. Submucous fibroids accounted for almost half (48.57\%) of the pathologies, followed by adhesions (28.57\%) and endometrial polyps (22.86\%) and they stated that SIS is a reliable, cost-effective, and safe diagnostic tool in the evaluation of the uterine cavity before assisted conception [3]. Seshadri et al. (2015) in the review stated that SIS is an established, reliable, and cost-effective method of diagnosing intrauterine abnormalities and plays an integral role in the baseline assessment of infertile women. SIS also can be complementary to other imaging modalities in infertile women [4]

\section{Conclusion}

The uterine cavities of most patients assessed by SIS before IVF were normal. The most common abnormalities in the uterine cavity findings were endometrial polyps, followed by synechiae and Müllerian duct anomalies. Most of these findings might compromise the outcomes of IVF procedures. SIS before IVF treatment can be a good option for evaluating uterus cavity before IVF to improve success rates.

\section{Acknowledgment}

The authors thank all of the teams Halim Fertility Center especially Diana Novia, S.Si, M. Si for their help and support to this study.

\section{References}

1. Hamilton JA, Larson AJ, Lower AM, Hasnain S, Grudzinskas JG Routine use of saline hysterosonography in 500 consecutive, 
unselected, infertile women. Hum Reprod. 1998;13(9):2463-73. https://doi.org/10.1093/humrep/13.9.2463

2. Allahbadia GN, Kadam K, Allahbadia S. Saline infusion sonohysterography (SIS). Rev Gynaecol Pract. 2004;4:181-93. https://doi.org/10.1016/j.rigp.2004.04.001

3. Obajimi G, Ogunkinle B. Routine saline infusion sonohysterography prior to assisted conception: A review of our initial experience. Ann Ibd Postgrad Med. 2016;14(2):99-102. PMid:28337095

4. Seshadri S, Khalil M, Osman A, Clough A, Jayaprakasan K, Khalaf $\mathrm{Y}$. The evolving role of saline infusion sonography (SIS) in infertility. Eur J Obstetr Gynecol Reprod Biol. 2015;185:66-73. https://doi.org/10.1016/j.ejogrb.2014.11.037 PMid:25528732

5. Parsons AK, Lense JJ. Sonohysterography for endometrial abnormalities: Preliminary results. J Clin Ultrasound. 1993;21(2):87-95. https://doi.org/10.1002/jcu.1870210203 PMid:8381140

6. Syrop $\mathrm{CH}$, Sahakian V. Transvaginal sonographic detection of endometrial polyps with fluid contrast augmentation. Obstet Gynecol 1992;79(6):1041-3. PMid:1579303

7. Soares SR, dos Reis MM, Camargos AF. Diagnostic accuracy of sonohysterography, transvaginal sonography, and hysterosalpingography in patients with uterine cavity diseases. Fertil Steril 2000;73(2):406-11. https://doi.org/10.1016/ s0015-0282(99)00532-4

PMid: 10685551

8. Nannini R, Chelo E, Branconi F, Tantini C, Scarselli GF. Dynamic echohysteroscopy: A new diagnostic technique in the study of female infertility. Acta Eur Fertil. 1981;12(2):165-71.

\section{PMid:7293673}

9. Sitimani A, Chawla I, Vohra P. Saline infusion sonography in evaluation of uterine cavity abnormalities in infertility: A comparative study. Int J Reprod Contracept Obstet Gynecol. 2016;5:2995-3000 https://doi.org/10.18203/2320-1770. ijrcog20162972

10. Lopes VM, Barguil JP, Lacerda TS, Souza AL, da Rocha Filho AM, Roller MF, et al. An overview of the results of hysterosonography prior to in vitro fertilization. JBRA Assist Reprod. 2017;21(4):302-5. https://doi.org/10.5935/1518-0557.20170051 PMid:28960053

11. Vilela JR, Cardoso MT, Franco Júnior JG, Pontes A. Sonohysterography accuracy versus transvaginal ultrasound in infertile women candidate to assisted reproduction techniques. Rev Bras Ginecol Obstet. 2012;34(3):122-7. PMid:22488496

12. Radwan P, Radwan M, Kozarzewski M, Polac I, Wilczyński J. Evaluation of sonohysterography in detecting endometrial polyps-241 cases followed with office hysteroscopies combined with histopathological examination. Wideochir Inne Tech Maloinwazyjne. 2014;9(3):344-50. https://doi.org/10.5114/ wiitm.2014.43024

PMid:25337156

13. Gupta N, Dwivedi S, Dwivedi GN, Sharma B, Gupta P. Uterine cavity evaluation in infertile patients with transvaginal sonography, saline infusion sonography and hysteroscopy. Int J Reprod Contracept Obstet Gynecol. 2016;5:1879-82. https:// doi.org/10.18203/2320-1770.ijrcog20161682

14. Sallam S. Screening saline infusion sonohysterography before ICSI and its effect on success rate of assisted reproduction. Int J Obstetr Gynaecol Res. 2016;3(9):455-61. 